Article

\title{
Chemical Analysis of Astragali Complanati Semen and Its Hypocholesterolemic Effect Using Serum Metabolomics Based on Gas Chromatography-Mass Spectrometry
}

\author{
Tung Ting Sham ${ }^{1}$, Huan Zhang ${ }^{1}$, Daniel Kam Wah Mok 1,2,3, Shun Wan Chan 1,2,4,* (D), \\ Jianhong $W u^{5}$, Songyun Tang ${ }^{6}$ and Chi On Chan $1,2, *$ \\ 1 Department of Applied Biology and Chemical Technology, The Hong Kong Polytechnic University, \\ Hong Kong, China; irene.sham@connect.polyu.hk (T.T.S.); huanzi101@163.com (H.Z.); \\ daniel.mok@polyu.edu.hk (D.K.W.M.) \\ 2 State Key Laboratory of Chinese Medicine and Molecular Pharmacology (Incubation), \\ Shenzhen 518057, China \\ 3 Food Safety and Technology Research Centre, Department of Applied Biology and Chemical Technology, \\ The Hong Kong Polytechnic University, Hong Kong, China \\ 4 Department of Food and Health Sciences, Faculty of Science and Technology, \\ Technological and Higher Education Institute of Hong Kong, Hong Kong, China \\ 5 Clinical Laboratory, Shenzhen Nanshan Center for Chronic Disease Control, Shenzhen 518000, China; \\ wujianhong_sz@126.com \\ 6 The Center Hospital of Hengyang, Hengyang 421001, China; tangsy55@163.com \\ * Correspondence: swchan@vtc.edu.hk (S.W.C.); on.chan@polyu.edu.hk (C.O.C.); \\ Tel.: +85-22-176-1482 (S.W.C.); +85-23-400-8876 (C.O.C.)
}

Received: 15 June 2017; Accepted: 18 July 2017; Published: 21 July 2017

\begin{abstract}
The hypocholesterolemic protective effect of the dried seed of Astragalus complanatus (ACS) was investigated in rats fed with normal diet, high cholesterol diet (HCD), and HCD plus $70 \%$ ethanol extract of ACS $(600 \mathrm{mg} / \mathrm{kg} /$ day) by oral gavage for four weeks. ACS extract was tested to be rich in antioxidants, which may be contributed to its high content of phenolic compounds. Consumption of ACS remarkably suppressed the elevated total cholesterol $(p<0.01)$ and LDL-C $(p<0.001)$ induced by HCD. Chemical constituents of ACS extract were analyzed by ultra-performance liquid chromatography coupled with electrospray ionization orbitrap mass spectrometry and the results showed that the ACS extract mainly consisted of phenolic compounds including flavonoids and flavonoid glycosides. In addition, based on the serum fatty acid profiles, elucidated using gas chromatography-mass spectrometry, free and esterified fatty acids including docosapentaenoic acid, adrenic acid, dihomo- $\gamma$-linolenic acid and arachidonic acid were regulated in ACS treatment group. Western blot results further indicated the protein expression of peroxisome proliferator-activated receptor alpha (PPAR $\alpha)(p<0.05)$ in liver was upregulated in ACS treatment group. To conclude, our results clearly demonstrated that ACS provides beneficial effect on lowering $\mathrm{HCD}$ associated detrimental change.
\end{abstract}

Keywords: Astragali Complanati Semen; serum metabolomics; hypercholesterolemia; mass spectrometry

\section{Introduction}

Astragali Complanati Semen (ACS), alternatively known as Flatstem Milkvetch Seed or ShaYuanZi in Chinese, is the dried ripe seeds of Astragalus complanatus Bunge (Leguminosae) [1], recorded in Chinese Pharmacopoeia [2] and Hong Kong Materia Medica Standards [3]. It is commonly used by 
Chinese medicine practitioners to tonify the "kidney" and assisting "yang", securing essence to reduce urination, and nourishing "liver" to improve eyesight [2]. ACS also possesses anti-hypertensive and anti-fibrosis activities. Its total flavonoids fraction has demonstrated anti-hypertensive action in rats via dilation of blood vessel by the blockade of the angiotensin II receptor [4] and anti-fibrotic action in rats associated with the regulation on lipid peroxidation and collagen synthesis [5]. Recently, the content of phenolic fraction in ACS has been shown to be highly correlated with the antioxidant activity [6]. It is believed that many of these therapeutic effects are attributed to its main constituents such as organic acids, flavonoids and its glycosides and triterpenoids.

Metabolomics aims at comprehensive characterization of endogenous metabolites and their variation in complex biological matrices such as plasma, urine and tissues extract by using high resolution nuclear magnetic resonance and mass spectrometry (MS) $[7,8]$. The methodology is particularly valuable for studying the systemic responses because of disease and drug treatment [9-13]. Thus, the use of metabolomics techniques should be a promising in understanding multi-component of herb extract in the treatment of metabolic diseases.

Hyperlipidemia is one of the major controllable risk factors for cardiovascular diseases (CVDs) [14]. It is characterized by high levels of one or more lipids and/or lipoproteins including atherogenic free fatty acids, triacylglycerols (TG), low density lipoprotein cholesterol (LDL-C), and apolipoprotein $\mathrm{B}$, and/or low level in high density lipoprotein cholesterol (HDL-C) in blood and all those values have been remained as clinical indicator for CVD in the society. Investigation of fatty acid profile in circulation could be reflected by cellular lipid homeostasis, which is characterized by the balance between processes that generate or deliver fatty acids and processes that utilize these molecules [15]. This approach has been proposed and utilized to study the obesity and other related metabolic diseases [16-18].

In the present work, fatty acid profiling including esterified fatty acids (EFAs) and free fatty acids (FFAs) were examined to study the metabolite changes in the serum samples collected from rats and investigate the therapeutic effect of ACS on high cholesterol diet (HCD)-induced hypercholesterolemic rats. Gas chromatography-mass spectrometry (GC-MS) results indicated that ACS regulated several fatty acids in serum after treatment. It was further confirmed that the protein expression level of hepatic peroxisome proliferator-activator receptor $\alpha(\operatorname{PPAR} \alpha)$ was upregulated by using Western blot. To the best of our knowledge, this is the first study demonstrating ACS supplement lowered circulating cholesterol levels, which was elevated due to HCD, by regulating the fatty acid metabolism via the metabolomics platform.

\section{Materials and Methods}

\subsection{Chemical and Solvents}

HPLC-graded acetonitrile, methanol and hexane were obtained from Fisher Scientific (Hampton, $\mathrm{NH}$, USA). Absolute ethanol was purchased from VWR chemicals (Radnor, PA, USA). Potassium hydroxide (Guangzhou Chemical Reagent Factory, Guangzhou, China), sulfuric acid ( $>98 \%$ purity, Chengdu Kelong Chemical Reagent Company, Chengdu, China) with and anhydrous sodium sulfate (Tianjin Damao Chemical Reagent Factory, Tianjin, China) used in the fatty acid derivatization process were analytical grade. L-ascorbic acid, 2,2-diphenyl-2-picrylhydrazyl (DPPH), Folin-Ciocalteu reagent, sodium carbonate, analytical graded formic acid and gallic acid ( $98 \%$ purity), heptadecanoic acid (C17:0, 99.0\% purity), heptadecanoic acid methyl ester (EC17:0, 99.0\% purity), oleic acid (C18:1n-9, $\geq 99.0 \%$ purity), oleic acid methyl ester (EC18:1n-9, $\geq 99.0 \%$ purity) and 37 fatty acid methyl ester (FAME) standard mixture (FAME Mix 37, Supelco) were commercially obtained from Sigma-Aldrich company (St. Louis, MO, USA).

The following chemicals for ultra-performance liquid chromatography coupled with electrospray ionization orbitrap mass spectrometry (UPLC-ESI-Orbitrap-MS) identification were used: formononetin (LKT Laboratories, St. Paul, MN, USA), isoquercitrin (Shanghai Tauto Biotech, Shanghai, 
China), complanatuside (Chengdu Must Biotechnology, Chengdu, China), kaempferol and quercetin (International Laboratory, South San Francisco, CA, USA). Roche Reagents were obtained from Roche diagnostics (Mannheim, Germany). Simvastatin $20 \mathrm{mg}$ tablets, a cholesterol-lowering drug, were purchased from Merck Sharp \& Dohme (Hangzhou, China) as our positive control in the animal study. Water was purified by a Milli-Q water-purification system (Millipore, MA, USA).

\subsection{Preparation of Extract of Astragali Complanati Semen (ACS)}

Ten batches of ACS were purchased from local market and Mainland China. The samples were authenticated by Dr. Sibao Chen based only on its morphological and microscopic characteristics [2]. All samples were then carried out fingerprint analysis based on Hong Kong Materia Medica Standards [3] and the obtained ten batches fingerprints were similar to each other. Figure 1 shows its morphological appearance of ACS used in this study (batch no: LSYZ-026-04) and its content of complanatuside was fulfilled the requirement of Chinese Pharmacopeia. ACS was ground into fine powder and mixed with $70 \%$ ethanol in a ratio 1:3 $(w / v)$. The mixture was let stand for $1 \mathrm{~h}$ and then boiled under reflux for $1 \mathrm{~h}$. Afterward, the supernatant was collected and the residue was re-extracted for two more times. Finally, supernatant was filtered. The filtrate was put in a rotary evaporator (Laborota4000, Heidolph, Germany) to remove the organic solvent at $50{ }^{\circ} \mathrm{C}$ water bath before lyophilizing in a freeze dryer (Labconco, Freezone 6, Kansas City, MO, USA). The extraction yield was $16.26 \%$. The dried ACS extract in powder form was stored at $-20{ }^{\circ} \mathrm{C}$ until it was redissolved in distilled water by ultrasonication before animal feeding.

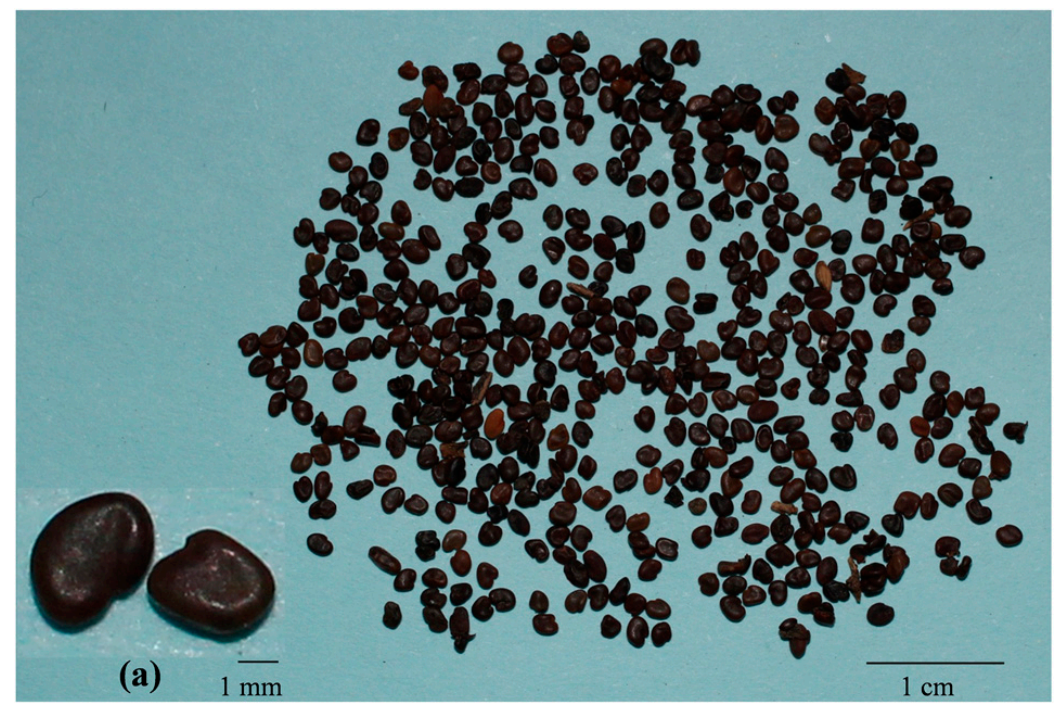

Figure 1. A photograph of Astragali Complanati Semen (ACS): (a) magnified ACS.

\subsection{Total Phenolic Quantification}

The total phenolic content in the dried ACS extract was determined by the Folin-Ciocalteu method, in accordance to the procedure of Singleton [19]. Dried ACS extract was redissolved in water to make extract solution in three suitable concentrations $(0.5,0.8$ and $1 \mathrm{mg} / \mathrm{mL})$. As for the standard curve, different concentrations of gallic acid ranged from $0.01-0.08 \mathrm{mg} / \mathrm{mL}$ were freshly prepared. $500-\mu \mathrm{L}$ Folin-Ciocalteu reagent was mixed with $400 \mu \mathrm{L}$ of sodium carbonate $(75.05 \mathrm{~g} / \mathrm{L})$ and then $100 \mu \mathrm{L}$ of the extract solution or standard solution were added. After $2 \mathrm{~h}$ of incubation at room temperature, the absorbance of the samples and standard solution were measured at $750 \mathrm{~nm}$ with GENESYS ${ }^{\mathrm{TM}} 20$ Visible Spectrophotometer (Thermo Fisher Scientific, West Palm Beach, FL, USA). Results were expressed as milligrams of gallic acid equivalents (GAE) per gram of dried ACS extract (mg GAE/g dried ACS extract). Content of total phenols of ACS was calculated using the following equation based on the 
calibration curve of absorbance against concentration of gallic acid: $y=19.18 x+0.0457$ and $R^{2}=0.9937$, where $y$ was the absorbance and $x$ was $\mathrm{mg}$ GAE/g dried ACS extract. The above process was repeated twice more. Data are presented as the mean \pm standard error of mean (SEM).

\subsection{DPPH Free Radical Scavenging Activity}

DPPH is a stable free radical in red-purple colour that can be scavenged by antioxidants, resulting in discoloration and the reduction of absorbance at $515 \mathrm{~nm}$. It has been widely applied to assess the antioxidative activities such as Chinese medicinal herbs [20,21]. The free radical scavenging activity (FRSA) of DPPH was measured by a modifcation from procedure described [22]. The FRSA of dried ACS extract was measured compared with vitamin C (L-ascorbic acid) as reference in parallel. Dried ACS extract redissolved in $70 \%$ ethanol by ultrasonication $(0.02-10 \mathrm{mg} / \mathrm{mL})$ and vitamin $C$ in water (0.002-1 mg/mL) was freshly prepared. Fifty microliters of different concentrations of ACS extraction solution and vitamin C solution was diluted 20 times with DPPH methanol solution (24 mg/L). Blank solvents were prepared as control. After vortexing, the solutions were kept in the dark for 1 hour at room temperature. Two hundred microliters of each solution was aliquoted to three wells of the same 96-well plate. The absorbance of DPPH solution was obtained at $515 \mathrm{~nm}$ by a spectrophotometer CLARIOstar (BMG LABTECH, Ortenberg, Germany). The FRSA was determinded in terms of the scavenging activity in percentage $(\mathrm{SR} \%)$ by the equation: $\mathrm{SR} \%=\left(1-\mathrm{A}_{\text {sample }} / \mathrm{A}_{\text {control }}\right) \times 100 \%$ where $\mathrm{A}_{\text {sample }}$ and $\mathrm{A}_{\text {control }}$ were the absorbance with and without samples respectively. The half maximal effective concentration $\left(\mathrm{EC}_{50}\right)$ of the samples were determined, which was the concentration of ACS or vitamin $C$ to achieve $50 \%$ of scavenging capacity. The above test was repeated twice more to get an average of the capability to scavenge the DPPH radicals.

\subsection{Chemical Analysis of ACS by Ultra-Performance Liquid Chromatography Coupled with Electrospray Ionization-Orbitrap-Mass Spectrometry (UPLC-ESI-Orbitrap-MS)}

$10 \mathrm{mg} / \mathrm{mL}$ of the dried ACS extract was prepared by redissolving $0.5 \mathrm{~g}$ of its extract with $50 \mathrm{~mL}$ $70 \%$ ethanol by ultrasonication for $20 \mathrm{~min}$. Then, $2 \mathrm{~mL}$ extraction solution was centrifuged at $13,000 \times g$ for 15 min prior to UPLC-ESI-Orbitrap-MS analysis. A 3- $\mu \mathrm{L}$ aliquot was injected into a Waters ACQUITY UPLC system. The separation was performed on a Waters ACQUITY UPLC BEH C 18 column $(2.1 \mathrm{~mm} \times 100 \mathrm{~mm}, 1.7 \mu \mathrm{m})$ with BEH C $_{18}$ guard column $(2.1 \mathrm{~mm} \times 5 \mathrm{~mm}, 1.7 \mu \mathrm{m}$, Waters Corporation, Milford, MA, USA). The mobile phase consisted of combinations of A $(0.1 \%$ formic acid in water, $v / v)$ and $\mathrm{B}(0.1 \%$ formic acid in acetonitrile, $v / v)$ at a flow rate of $0.3 \mathrm{~mL} / \mathrm{min}$ with elution gradient as follows: $0 \mathrm{~min}, 10 \% \mathrm{~B} ; 12 \mathrm{~min}, 40 \% \mathrm{~B} ; 15 \mathrm{~min}, 60 \% \mathrm{~B} ; 17-19.5 \mathrm{~min}, 95 \% \mathrm{~B}$. A 3-min post-run time was set to fully equilibrate the column. Column and sample chamber temperature were $35^{\circ} \mathrm{C}$ and $6{ }^{\circ} \mathrm{C}$, respectively.

Mass spectrometry analysis was achieved by a Thermo Scientific Orbitrap Fusion Lumos Tribrid mass spectrometer equipped with a heated electrospray ionization (H-ESI) interface (Thermo Fisher, Waltham, MA, USA). The mass-spectrometric conditions were optimized as follows: spray voltage, $2.3 \mathrm{kV}$ in negative $\mathrm{H}$-ESI mode; ion transfer tube and vaporizer temperature, $300{ }^{\circ} \mathrm{C}$. Nitrogen gas $(\geq 99.999 \%)$ was used as the sheath gas and the aux gas with flow rate of 30 and 10 arbitrary unit respectively. The instrument was operated in data-dependent acquisition mode, with full MS scans over a mass range of $m / z$ 100-1000 with detection in the Orbitrap (120k resolution) and with auto gain control (AGC) set to 80,000 and a maximum injection time at $100 \mathrm{~ms}$. In each cycle (0.6 s) of data-dependent acquisition analysis, the most intense ions with intensity threshold above 20,000 were selected for fragmentation at normalized collision energy of $30 \pm 10 \%$ higher energy collisional dissociation. The number of selected precursor ions for fragmentation was determined by the "Top Speed" acquisition algorithm. Fragment ion spectra were acquired in the Orbitrap (30k resolution) with an AGC of 20,000 and a maximum injection time of $35 \mathrm{~ms}$ for Orbitrap $\mathrm{MS}^{2}$ detection. All data analysis was carried out using Thermo Xcalibur Qual Browser software (Thermo Fisher Scientific). 


\subsection{Animals and Experimental Treatment}

Thirty-two male Sprague Dawley rats $(170 \pm 10 \mathrm{~g})$ supplied by Guangdong Provincial Medical Laboratory Animal Center (Guangzhou, China) were housed under specific pathogen free standard conditions (temperature at $24 \pm 2{ }^{\circ} \mathrm{C}$, humidity at $60 \pm 10 \%$ and light from 6 a.m. to 6 p.m.) with free access to water and rat chow. After acclimation for a week in this housing environment, the rats were randomly divided into four groups ( $n=8$ /group): (1) normal control: a control group fed with normal rat chow obtained from Guangdong Provincial Medical Laboratory Animal Center (Guangzhou, China) (rat chow composition: protein $(\sim 14 \%)$, fat $(\sim 10 \%)$, and carbohydrate $(\sim 76 \%)$ ); (2) HCD model: a model group fed with HCD, which is the standard rat chow supplemented with $1 \%$ cholic acid, $2 \%$ pure cholesterol and $5.5 \%$ peanut oil; (3) positive control: a treatment group that received HCD plus simvastatin ( $3 \mathrm{mg} / \mathrm{kg}$, body weight/day); (4) ACS: a study treatment group that received HCD plus ACS (600 mg/kg, body weight/day); The rats were administered with distilled water (vehicle) or their corresponding treatments by oral gavage once every morning for four weeks. At the end of the experimental period, the rats were fasted overnight and killed by cervical dislocation. Blood and livers were then collected for further analysis. The experimental protocol was conducted under the animal license issued by the Health Department of the Hong Kong SAR Government and the Animal Subjects Ethics Sub-committee (ASESC number 01/21) of the Hong Kong Polytechnic University (Hong Kong, China).

\subsection{Analysis of Serum Lipid Profiles}

Blood was collected in centrifuge tubes by cardiac puncture and allowed to clot for $2 \mathrm{~h}$. Afterward, the clotted blood was centrifuged $(3000 \times \mathrm{g})$ at $4{ }^{\circ} \mathrm{C}$ for $10 \mathrm{~min}$ to obtain the serum. Serum was stored at $-80^{\circ} \mathrm{C}$ freezer before measurement of lipid profiles. Content of total serum cholesterol, triacylglycerols, LDL-C, and HDL-C were determined by the ALYCON systems using Roche Reagents (Roche diagnostics, Mannheim, Germany). The atherogenic index was calculated by this equation: atherogenic index $=$ (total serum cholesterol - HDL-C) $/$ HDL-C.

\subsection{Metabolomics Analysis}

\subsubsection{GC-MS Sample Preparation Method}

The methods reported [23] were used as a starting point for the method development. A two-step methylation of EFAs and FFAs fractions in each serum without a protein-removal step was applied. 200- $\mu \mathrm{L}$ serum aliquot was spiked with internal standards ( $20 \mu \mathrm{L}, 3 \mathrm{mM}$ EC17:0 and C17:0 in methanol). Trace amount of anhydrous sodium sulfate was added to remove water in the serum. In the first step, $2 \mathrm{~mL}$ of $0.4 \mathrm{M}$ methanolic potassium hydroxide was added to the serum aliquot, vortexed for $1 \mathrm{~min}$ and let stand at room temperature for $20 \mathrm{~min}$. Then, $2 \mathrm{~mL} n$-hexane was added, vortexed for $30 \mathrm{~s}$ and the upper layer of hexane phase was isolated. The hexane extraction was done in twice and combined to isolate EFA methyl esters. In the second step, $2 \mathrm{~mL} \mathrm{10 \%} \mathrm{methanolic} \mathrm{sulfuric} \mathrm{acid} \mathrm{was}$ added to the serum phase and vortexed for $1 \mathrm{~min}$. The mixture was incubated in a water bath at $70{ }^{\circ} \mathrm{C}$ for $30 \mathrm{~min}$. Isolation of FFA methyl esters by hexane extraction was the same as EFA methyl esters. The two hexane phases of EFA and FFA methyl esters were dried with nitrogen gas separately. The dried sample was finally reconstituted with $1 \mathrm{~mL} n$-hexane before GC-MS analysis.

\subsubsection{GC-MS Condition}

The GC-MS system was an Agilent 6890N GC/5975C VL MSD system equipped with an Agilent 7683 Automatic Liquid Sampler (Agilent technologies, Inc., Santa Clara, CA, USA). The column was a DB-WAX column ( $30 \mathrm{~m} \times 0.25 \mathrm{~mm}, 0.25 \mu \mathrm{m}$; Agilent J\&W Scientific, Folsom, CA, USA). The inlet temperature of the GC was kept at $240{ }^{\circ} \mathrm{C}$. Helium ( $\left.\geq 99.999 \%\right)$ was used as carrier gas with a constant linear velocity of $1.0 \mathrm{~mL} / \mathrm{min}$. $1-\mu \mathrm{L}$ aliquot was injected in splitless mode. The temperature program that was optimized for GC was as follows: the initial oven temperature as $70{ }^{\circ} \mathrm{C}$, held for $1 \mathrm{~min}$; 
$20{ }^{\circ} \mathrm{C} / \mathrm{min}$ to $150{ }^{\circ} \mathrm{C} ; 10{ }^{\circ} \mathrm{C} / \mathrm{min}$ to $190{ }^{\circ} \mathrm{C} ; 3^{\circ} \mathrm{C} / \mathrm{min}$ to $220^{\circ} \mathrm{C} ; 5{ }^{\circ} \mathrm{C} / \mathrm{min}$ to $230{ }^{\circ} \mathrm{C} ; 230{ }^{\circ} \mathrm{C}$ held for $12 \mathrm{~min}$. The MS conditions were as follows: electron impact mode at ionization energy of $70 \mathrm{eV}$; ion source temperature at $230{ }^{\circ} \mathrm{C}$; transfer line temperature at $240{ }^{\circ} \mathrm{C}$; full scan mode in $\mathrm{m} / \mathrm{z}$ range $35-550$ with $0.3 \mathrm{~s} / \mathrm{scan}$ velocity. The solvent delay was $3 \mathrm{~min}$.

\subsubsection{Data Processing and Analysis}

Peak identification of GC-MS data was carried out by comparing the retention time of authentic standards (37 FAME mix) and the mass spectra with NIST11 library. The peak detection and deconvolution were performed by Automated Mass Spectral Deconvolution and Identification System (AMDIS) v2.7 (NIST, Gaithersburg, MD, USA). Peak area was normalized by the spiked internal standard in each sample. Partial least squares discriminant analysis (PLS-DA) of the normalized peak area after pareto-scaling was performed by the Extended Statistical tool (EZinfo v2.0 software, Umetrics AB, Umeå, Sweden). Potential markers of interest were obtained based on their Variable Importance in the Projection (VIP) values of PLS-DA (threshold of VIP $\geq 1$ ).

\subsection{Western Blot Immunoreactivity Assay}

Hepatic peroxisome proliferator-activator receptor $\alpha(\operatorname{PPAR} \alpha)$ and $\beta$-actin protein levels were quantified using immunoblotting procedures. Protein extracts $(40 \mu \mathrm{g})$ of rat liver tissue were applied to $10 \%$ SDS polyacrylamide gels and transferred to polyvinylidene difluoride membranes, which were blotted overnight at $4{ }^{\circ} \mathrm{C}$ with non-fat milk solution. The membrane was probed with primary antibody (1:1000) followed by secondary antibody and visualized using an enhanced chemiluminescence (ECL) plus kit (Amersham Bioscience, Aylesbury, UK) and exposed to FujiFilm autoradiographic films according to the manufacturer's protocol. Densitometric measurements of band intensity in the Western blots were performed using Quantity One Software (Bio-Rad, Hercules, CA, USA).

\subsection{Statistical Analysis}

Data were expressed as means \pm standard error of mean (SEM) and $n$ denotes the number of replications for each data point. Statistical differences of multiple groups were analyzed at a univariate level by one-way analysis of variance (ANOVA) followed by Tukey HSD post hoc test using GraphPad Prism 5.02 (San Diego, CA, USA). A value of probability $p<0.05$ was considered statistically significant.

\section{Results}

\subsection{Chemical Constituents of ACS Extract}

The total phenolic content of the dried ACS extract was determined to be $33.9 \pm 0.7 \mathrm{mg} \mathrm{GAE} / \mathrm{g}$ extract. ACS possessed high antioxidant property with $\mathrm{EC}_{50}=37.30 \pm 0.61 \mu \mathrm{g} / \mathrm{mL}$ by DPPH assay, with vitamin $\mathrm{C}$ (ascorbic acid, $\mathrm{EC}_{50}=1.96 \pm 0.16 \mu \mathrm{g} / \mathrm{mL}$ ) as reference (Figure 2).

In addition, 36 components including amino acids, phenolic and its glycosides, and flavonoids and its glycosides were tentatively identified by UPLC-ESI-Orbitrap-MS after comparison of the retention time, accurate $m / z$ and mass fragmentation pattern with authentic standards, ACS literatures [6,24,25] as well as online database. The base peak chromatogram of extract of ACS was depicted in Figure 3 and a summary of phytochemicals detected by UPLC-ESI-Orbitrap-MS was shown in Table 1. 


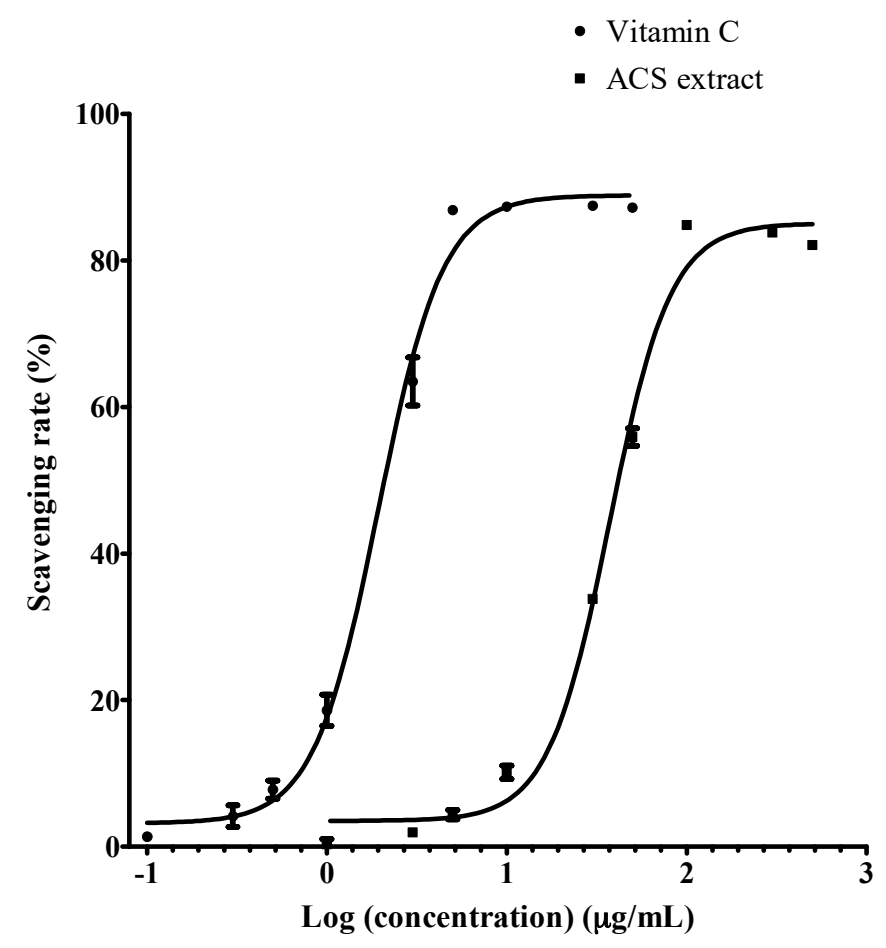

Figure 2. The free radical scavenging capacity of vitamin $\mathrm{C}$ and ACS against their concentration [mean \pm standard error of mean (SEM), $n=3$ ].

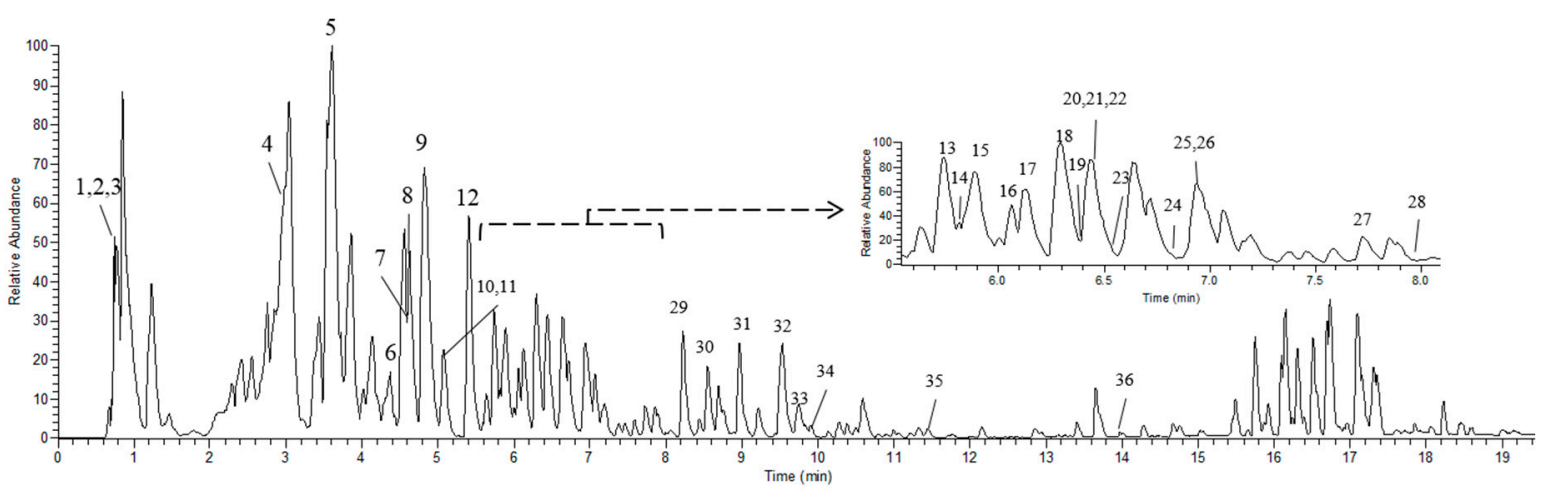

Figure 3. The base peak intensity chromatogram of 70\% ethanol solution of the dried ACS extract analyzed by ultra-performance liquid chromatography coupled with electrospray ionization orbitrap mass spectrometry (UPLC-ESI-Orbitrap-MS) in negative ionization mode. 
Table 1. Identification of metabolites from $70 \%$ ethanol extract of ACS analyzed by UPLC-ESI-Orbitrap-MS

\begin{tabular}{|c|c|c|c|c|c|c|c|c|}
\hline $\begin{array}{l}\text { Peak } \\
\text { Number }\end{array}$ & $\begin{array}{c}\text { Retention } \\
\text { Time (min) }\end{array}$ & Identity (Common Name) & Theoretical $\mathrm{m} / \mathrm{z}$ & Detected $m / z$ & $\begin{array}{l}\text { Mass Error } \\
\text { (ppm) }\end{array}$ & Adduct & $\begin{array}{l}\text { Molecular } \\
\text { Formula }\end{array}$ & Mass Fragments \\
\hline 1 & 0.72 & L-Arginine* & 173.1044 & 173.1042 & -1.4 & {$[\mathrm{M}-\mathrm{H}]^{-}$} & $\mathrm{C}_{6} \mathrm{H}_{14} \mathrm{~N}_{4} \mathrm{O}_{2}$ & $131.0823,156.0773$ \\
\hline 2 & 0.76 & L-Aspartic acid * & 132.0302 & 132.0298 & -2.7 & {$[\mathrm{M}-\mathrm{H}]^{-}$} & $\mathrm{C}_{4} \mathrm{H}_{7} \mathrm{NO}_{4}$ & 115.0032 \\
\hline 3 & 0.77 & L-Glutamic acid * & 146.0459 & 146.0456 & -2.2 & $\begin{array}{l}{[\mathrm{M}-\mathrm{H}]^{-}} \\
{[\mathrm{M}}\end{array}$ & $\mathrm{C}_{5} \mathrm{H}_{9} \mathrm{NO}_{4}$ & 128.0348 \\
\hline 4 & 2.90 & Myricetin 3,4'-diglucopyranoside (Complanatoside A) & 641.1359 & 641.1358 & -0.2 & {$[\mathrm{M}-\mathrm{H}]^{-}$} & $\mathrm{C}_{27} \mathrm{H}_{30} \mathrm{O}_{18}$ & $317.0296,479.0825,623.1239$ \\
\hline 5 & 3.61 & Myricetin-3-O- $\beta$-D-glucopyranoside isomer & 479.0831 & 479.0833 & 0.5 & {$[\mathrm{M}-\mathrm{H}]^{-}$} & $\mathrm{C}_{21} \mathrm{H}_{20} \mathrm{O}_{13}$ & $151.0031,178.9981,316.02197$ \\
\hline 6 & 4.37 & $\begin{array}{l}\text { Calycosin 7-O- } \beta \text {-D-glucopyranoside/Calycosin } \\
\text { 7- }- \text {-D-galactopyranoside }\end{array}$ & 491.1195 & 491.1193 & -0.4 & {$[\mathrm{M}+\mathrm{HCOO}]^{-}$} & $\mathrm{C}_{22} \mathrm{H}_{22} \mathrm{O}_{10}$ & $268.0375,283.0611,329.1140,447.1292$ \\
\hline 7 & 4.58 & 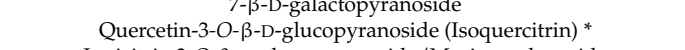 & 463.0882 & 463.0881 & -0.2 & {$[\mathrm{M}-\mathrm{H}]^{-}$} & $\mathrm{C}_{21} \mathrm{H}_{20} \mathrm{O}_{12}$ & $151.0031,178.9981,271.0244,300.0271$ \\
\hline 8 & 4.63 & Laricitrin 3-O- $\beta$-D-glucopyranoside/Myricomplanoside & 493.0988 & 493.0987 & -0.3 & {$[\mathrm{M}-\mathrm{H}]^{-}$} & $\mathrm{C}_{22} \mathrm{H}_{22} \mathrm{O}_{13}$ & $151.0031,178.9981,315.0142,330.0377$ \\
\hline 9 & 4.82 & $\begin{array}{l}\text { Myricetin-3-O- } \beta \text {-D-glucopyranoside/Myricetin } \\
\text { 5'-O- } \beta \text {-D-glucopyranoside/isomer }\end{array}$ & 479.0831 & 479.0831 & 0.0 & {$[\mathrm{M}-\mathrm{H}]^{-}$} & $\mathrm{C}_{21} \mathrm{H}_{20} \mathrm{O}_{13}$ & $151.0031,178.9981,299.0190,317.0298$ \\
\hline 10 & 5.07 & $\begin{array}{l}\text { Kaempferol 3-O- } \beta \text {-rutinoside (Nicotiflorin) /Kaempferol } \\
\text { 3-neohesperidoside/isomer }\end{array}$ & 593.1512 & 593.1510 & -0.3 & {$[\mathrm{M}-\mathrm{H}]^{-}$} & $\mathrm{C}_{27} \mathrm{H}_{30} \mathrm{O}_{15}$ & $151.0032,178.9982,285.0400,447.1192$ \\
\hline 11 & 5.07 & Quercetin 3-O- $\alpha$-L-arabinopyranoside & 433.0776 & 433.0774 & -0.4 & {$[\mathrm{M}-\mathrm{H}]^{-}$} & $\mathrm{C}_{20} \mathrm{H}_{18} \mathrm{O}_{11}$ & $\begin{array}{l}151.0031,178.9982,255.0294,271.0244, \\
300271\end{array}$ \\
\hline 12 & 5.41 & Kaempferol 3-O- $\beta$-D-glucopyranoside (Astragalin) & 447.0933 & 447.0933 & -0.1 & {$[\mathrm{M}-\mathrm{H}]^{-}$} & $\mathrm{C}_{21} \mathrm{H}_{20} \mathrm{O}_{11}$ & $227.0344,255.0295,284.0322$ \\
\hline 13 & 5.74 & Kaempferol 3-O- $\alpha$-L-arabinopyranoside & 417.0827 & 417.0827 & -0.1 & {$[\mathrm{M}-\mathrm{H}]^{-}$} & $\mathrm{C}_{20} \mathrm{H}_{18} \mathrm{O}_{10}$ & $\begin{array}{l}151.0032,178.9980,227.0344,255.0294, \\
284.0322\end{array}$ \\
\hline 14 & 5.84 & Kaempferide/Rhamnocitrin & 299.0561 & 299.0557 & -1.2 & {$[\mathrm{M}-\mathrm{H}]^{-}$} & $\mathrm{C}_{16} \mathrm{H}_{12} \mathrm{O}_{6}$ & $271.0247,284.0322$ \\
\hline 15 & 5.88 & Calycosin & 283.0612 & 283.0611 & -0.4 & {$[\mathrm{M}-\mathrm{H}]^{-}$} & $\mathrm{C}_{16} \mathrm{H}_{12} \mathrm{O}_{5}$ & $211.0396,224.0474,268.0374$ \\
\hline 16 & 6.06 & Myricetin & 317.0303 & 317.0299 & -1.3 & {$[\mathrm{M}-\mathrm{H}]^{-}$} & $\mathrm{C}_{15} \mathrm{H}_{10} \mathrm{O}_{8}$ & $\begin{array}{l}151.0032,165.0189,178.9981,271.0244, \\
289.0244,299.0195\end{array}$ \\
\hline 17 & 6.12 & Kaempferol 3-O- $\beta$-rutinoside isomer & 593.1512 & 593.1510 & -0.4 & {$[\mathrm{M}-\mathrm{H}]^{-}$} & $\mathrm{C}_{27} \mathrm{H}_{30} \mathrm{O}_{15}$ & $283.0245,298.0480$ \\
\hline 18 & 6.29 & Laricitrin 3-O- $\beta$-D-glucopyranoside/Myricomplanoside & 493.0988 & 493.0987 & -0.1 & {$[\mathrm{M}-\mathrm{H}]^{-}$} & $\mathrm{C}_{22} \mathrm{H}_{22} \mathrm{O}_{13}$ & $151.0031,178.998,316.0219,331.0455$ \\
\hline 19 & 6.39 & $\begin{array}{l}\text { Quercetin-4'-O- } \beta \text {-D-glucopyranoside/6-Hydroxykaempferol } \\
\text { 7-glucopyranoside/isomer }\end{array}$ & 463.0882 & 463.0879 & -0.7 & {$[\mathrm{M}-\mathrm{H}]^{-}$} & $\mathrm{C}_{21} \mathrm{H}_{20} \mathrm{O}_{12}$ & $151.0031,178.9981,301.0349$ \\
\hline 21 & 6.44 & Rhamnocitrin-34'-O-diglucopyranoside (Complanatuside) * & 669.1672 & 669.1673 & 0.1 & {$[\mathrm{M}+\mathrm{HCOO}]^{-}$} & $\mathrm{C}_{28} \mathrm{H}_{32} \mathrm{O}_{16}$ & $299.0557,461.1085$ \\
\hline 22 & 6.45 & Rhamnocitrin-3,4--O-diglucopyranoside (Complanatuside) * & 623.1618 & 623.1617 & -0.1 & {$[\mathrm{M}-\mathrm{H}]^{-}$} & $\mathrm{C}_{28} \mathrm{H}_{32} \mathrm{O}_{16}$ & $299.0559,461.1082$ \\
\hline 23 & 6.51 & Calycosin 7- $\beta$-D-glucopyranoside/Calycosin 7-galactopyranoside & 445.1140 & 445.1137 & -0.7 & {$[\mathrm{M}-\mathrm{H}]^{-}$} & $\mathrm{C}_{22} \mathrm{H}_{22} \mathrm{O}_{10}$ & 283.0606 \\
\hline 24 & 6.82 & Calycosin 7- $\beta$-D-glucopyranoside/Calycosin 7-galactopyranoside & 445.1140 & 445.1137 & -0.6 & {$[\mathrm{M}-\mathrm{H}]^{-}$} & $\mathrm{C}_{22} \mathrm{H}_{22} \mathrm{O}_{10}$ & 283.0606 \\
\hline 25 & 6.94 & $\begin{array}{l}\text { Rhamnocitrin-3-O- } \beta \text {-D-glucopyranoside/Kaempferide } \\
\text { 7-O- } \beta \text {-D-glucopyranoside }\end{array}$ & 461.1089 & 461.1087 & -0.4 & {$[\mathrm{M}-\mathrm{H}]^{-}$} & $\mathrm{C}_{22} \mathrm{H}_{22} \mathrm{O}_{11}$ & $165.0187,299.0564$ \\
\hline 26 & 6.94 & $\begin{array}{c}\text { Neocomplanoside/ / } 6^{\prime \prime}-\mathrm{O} \text {-acetyl-kaemprefide-7-O- } \beta \text {-D-glucopyranoside/ } \\
\text { 6"-O-acetyl-pratensein-7-O- } \beta \text {-D-glucopyranoside }\end{array}$ & 503.1195 & 503.1193 & -0.4 & {$[\mathrm{M}-\mathrm{H}]^{-}$} & $\mathrm{C}_{24} \mathrm{H}_{24} \mathrm{O}_{12}$ & $283.0245,299.0555,461.1088$ \\
\hline 27 & 7.72 & Calycosin 7- $-\beta$-D-glucopyranoside/Calycosin 7-galactoside & 445.114 & 445.1137 & -0.7 & {$[\mathrm{M}-\mathrm{H}]^{-}$} & $\mathrm{C}_{22} \mathrm{H}_{22} \mathrm{O}_{10}$ & 283.0606 \\
\hline 28 & 7.97 & $\begin{array}{l}\text { Quercetin * } \\
*\end{array}$ & 301.0350 & 301.0350 & -1.3 & {$[\mathrm{M}-\mathrm{H}]^{-}$} & $\mathrm{C}_{15} \mathrm{H}_{10} \mathrm{O}_{7}$ & $121.0290,151.0032,178.9981,273.0403$ \\
\hline 29 & 8.22 & Kaempferol $3-O-\beta$-rutinoside isomer & 593.1512 & 593.1513 & 0.1 & {$[\mathrm{M}-\mathrm{H}]^{-}$} & $\mathrm{C}_{27} \mathrm{H}_{30} \mathrm{O}_{15}$ & $283.0243,298.0478$ \\
\hline 30 & 8.55 & Formononetin 7-O-(6"-acetylglucoside)/ isomer & 517.1351 & 517.1351 & 0.0 & {$[\mathrm{M}+\mathrm{HCOO}]^{-}$} & $\mathrm{C}_{24} \mathrm{H}_{24} \mathrm{O}_{10}$ & $252.0422,267.0659$ \\
\hline 31 & 8.97 & $\begin{array}{l}\text { Rhamnocitrin-3-O- } \beta \text {-D-glucopyranoside/Kaempferide } \\
\text { 7-O- } \beta \text {-D-glucopyranoside }\end{array}$ & 461.1089 & 461.1090 & 0.3 & {$[\mathrm{M}-\mathrm{H}]^{-}$} & $\mathrm{C}_{22} \mathrm{H}_{22} \mathrm{O}_{11}$ & 299.0555 \\
\hline 32 & 9.53 & Neocomplanoside/ $6^{\prime \prime}-O$-acetyl-kaempferide-7-O- $\beta$-D-glucoside/ & 503.1195 & 503.1194 & -0.1 & {$[\mathrm{M}-\mathrm{H}]^{-}$} & $\mathrm{C}_{24} \mathrm{H}_{24} \mathrm{O}_{12}$ & 283.0244, 299.0555, 461.1096 \\
\hline 33 & 9.72 & $\begin{array}{l}0-0 \text {-acetyl-pratal } \\
\text { Kaempferol * }\end{array}$ & 285.0405 & 285.0405 & -0.1 & {$[\mathrm{M}-\mathrm{H}]^{-}$} & $\mathrm{C}_{15} \mathrm{H}_{10} \mathrm{O}_{6}$ & $185.0602,229.0514,257.0457$ \\
\hline 34 & 9.89 & Formononetin 7-O-(6"-acetylglucoside)/isomer & 517.1351 & 517.1348 & -0.6 & {$\left[\mathrm{M}+\mathrm{HCOO}^{-}\right.$} & $\mathrm{C}_{24} \mathrm{H}_{24} \mathrm{O}_{10}$ & $252.0423,267.0659$ \\
\hline 35 & 11.48 & Formononetin * & 267.0663 & 267.0663 & 0.0 & {$[\mathrm{M}-\mathrm{H}]^{-}$} & $\mathrm{C}_{16} \mathrm{H}_{12} \mathrm{O}_{4}$ & $223.0397,252.0424$ \\
\hline 36 & 13.96 & Kaempferide/Rhamnocitrin/Isokaempferide & 299.0561 & 299.0559 & -0.6 & {$[\mathrm{M}-\mathrm{H}]^{-}$} & $\mathrm{C}_{16} \mathrm{H}_{12} \mathrm{O}_{6}$ & $165.0188,271.0608,284.0321$ \\
\hline
\end{tabular}

${ }^{*}$ Peaks were identified by standards. Others were tentatively identified with references and online database. 


\subsection{Effect on Serum Lipid Profiles}

The serum lipid profiles of different treatment groups by the end of the experiment were summarized in Figure 4. In rats fed with $\mathrm{HCD}$, there were significant elevations in total serum cholesterol $(p<0.001)$, LDL-C $(p<0.001)$ and atherogenic index $(p<0.001)$, as compared with the control group. Treating the animals with ACS extract could suppress the increased serum total cholesterol $(p<0.01)$ and LDL-C $(p<0.001)$ induced by the HCD. However, ACS extracts used did not return the levels of serum total cholesterol and LDL-C back to normal (those of the control group). Both the ACS extract $(p<0.01)$ and simvastatin $(p<0.05)$ supplementation could significantly decrease the atherogenic index which is a parameter to measure the risk of coronary heart disease.

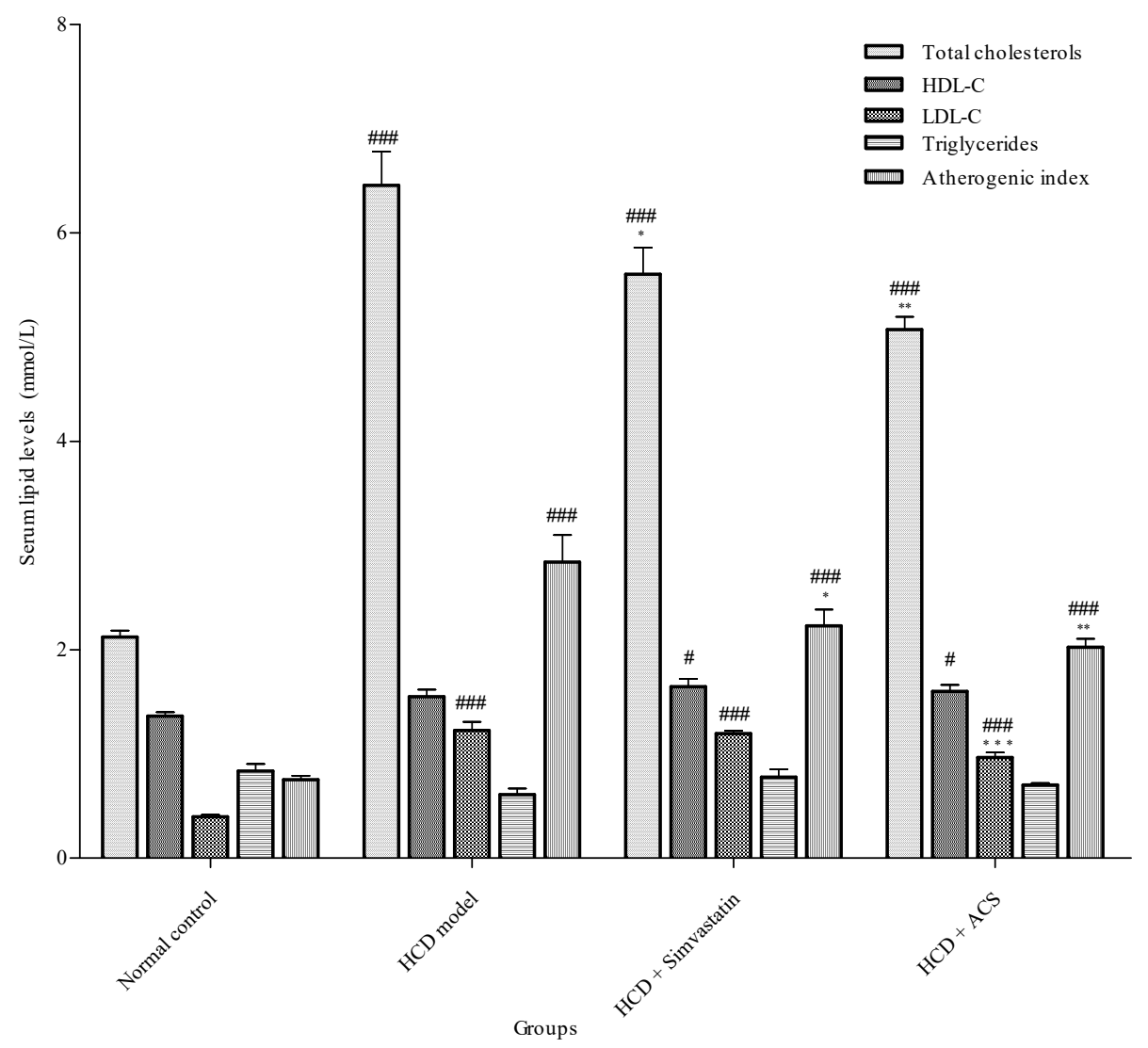

Figure 4. Serum lipid levels and atherogenic indexes of rats. Data are expressed as means \pm SEM, ( $n=5-7)$. One-way analysis of variance (ANOVA), Tukey HSD post hoc test. \# $p<0.05$ and \#\#\# $p<0.001$ represent significant differences when compared with the normal control group. ${ }^{*} p<0.05,{ }^{* *} p<0.01$, and ${ }^{* * *} p<0.001$ represent significant differences when compared with the high cholesterol diet (HCD) group.

\subsection{Stability of Metabolomics Platform}

The stability of GC-MS detection was assessed by multiple injections of the same pooled sample after extraction at room temperature within $24 \mathrm{~h}$. The coefficient of variation of EFAs and FFAs were $4.04-11.69 \%$ and $4.57-13.54 \%$, respectively. Recovery $(n=5)$ by spiking EC18:1n-9c and C18:1n-9c (the same concentration as serum) to the serum was also performed and the obtained results were $95.31 \pm 2.87 \%$ and $93.08 \pm 3.47 \%$ (mean \pm relative standard deviation).

\subsection{Effects on Metabolite Changes}

Total of 21 EFA and 21 FFA were identified in the serum samples by GC-MS (Table 2 and Figure 5). Obvious separation trend among the control, HCD, simvastatin treatment and ACS treatment groups 
was observed in partial least squares-discrimination analyses (PLS-DAs) being applied (Figure 6a). The cumulative $R^{2} Y$ and $Q^{2}$ were 0.57 and 0.50 , respectively, and no overfitting was observed.
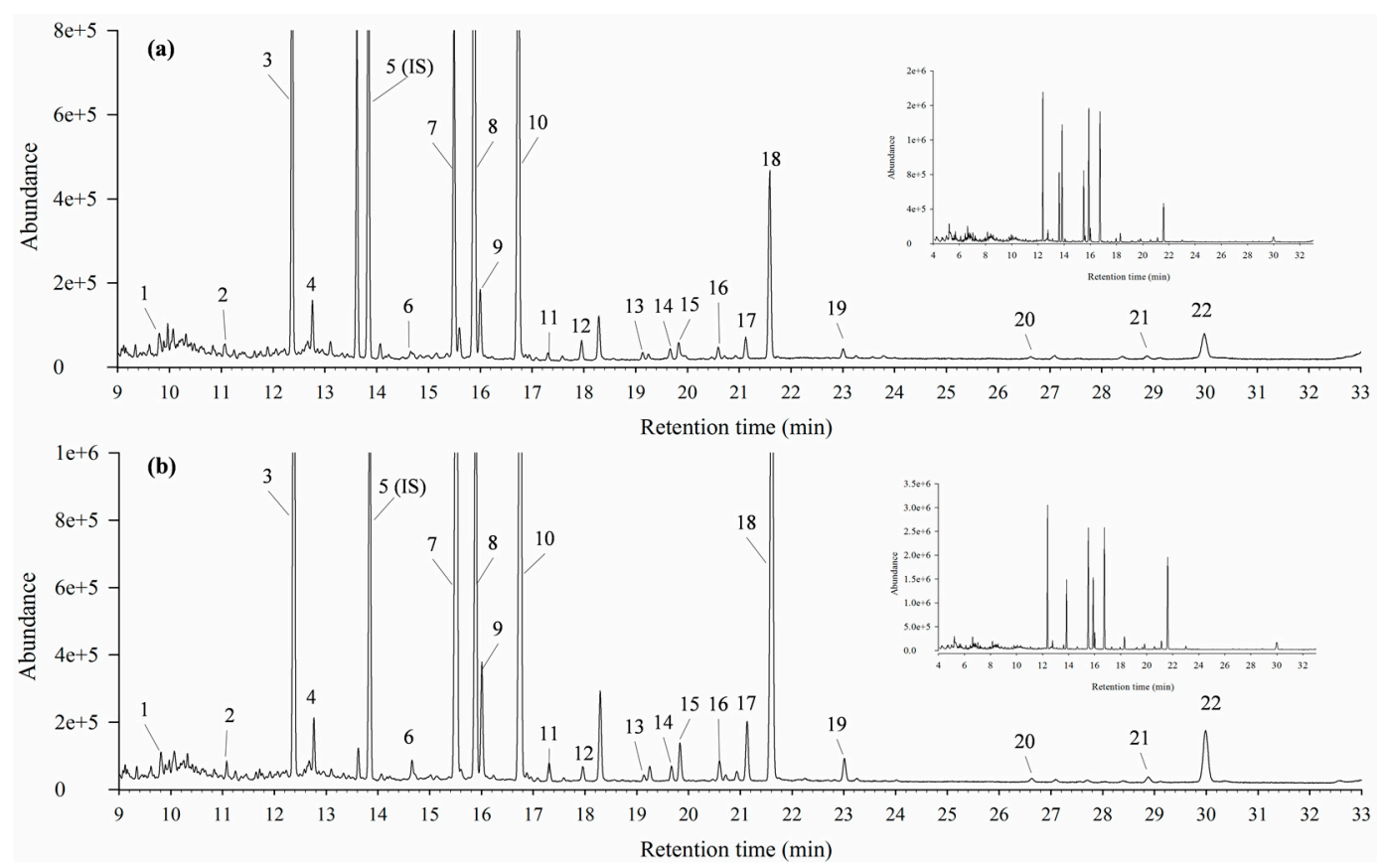

Figure 5. Typical total ion chromatograms of rat serums from HCD group by gas chromatography-mass spectrometry (GC-MS): (a) free fatty acids (FFAs) and (b) esterified fatty acids (EFAs). IS, internal standard.

For the multivariate analysis using PLS-DA, VIP was chosen to find out those peaks in GC-MS data with VIP value $\geq 1$. After screening, 12 differential metabolites were further evaluated and Figure $6 \mathrm{~b}$ clearly visualizes the relative content of differential EFAs and FFAs with VIP $\geq 1$ in different groups to analyze their hierarchical cluster by heat map. Esterified 11-eicosenoic acid (EC20:1n-9) and nine FFAs were higher in all three HCD-fed groups while free docosapentaenoic acid (DPA) (C22:5n-3), esterified adrenic acid (EC22:4n-6) and esterified DPA were only increased in both simvastatin and ACS treated groups compared with HCD group $(p<0.05)$.

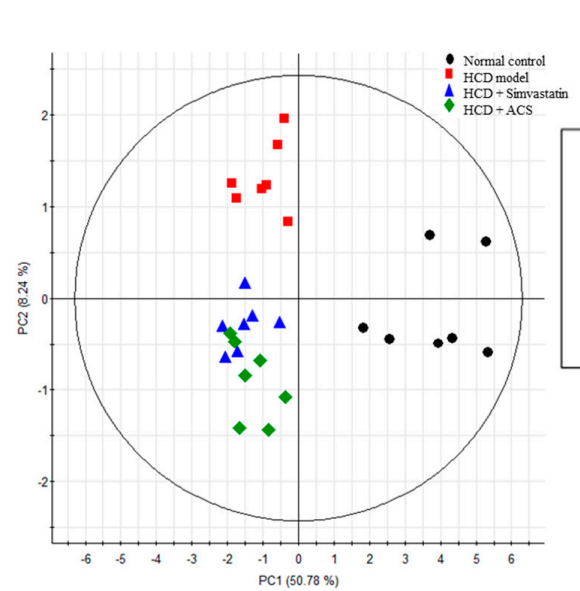

(a)

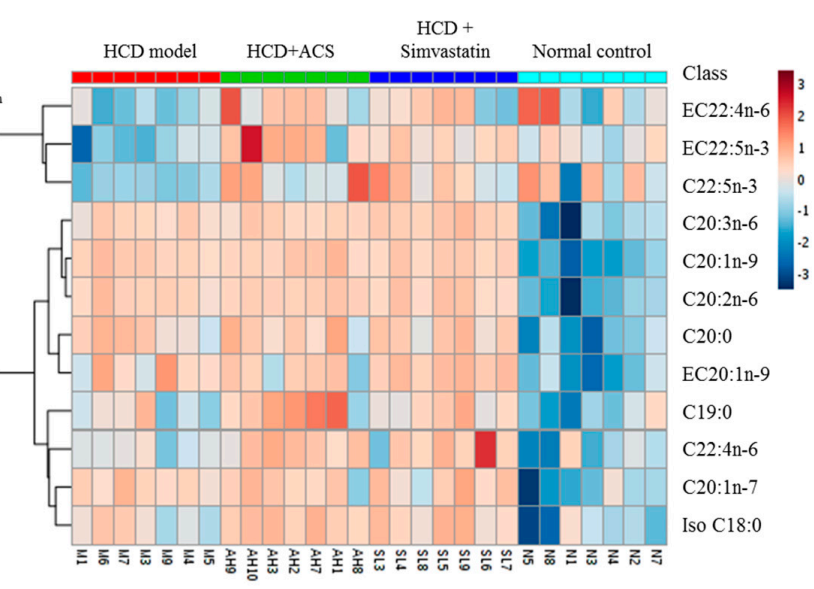

(b)

Figure 6. GC-MS results of FFAs and EFAs of rat serum: (a) the partial least squares discriminant analysis (PLS-DA) score plot of FFAs and EFAs level data sets (after automatic transformation). $\mathrm{R}^{2} \mathrm{Y}$ $($ cum $)=0.57, \mathrm{Q}^{2}$ (cum) 0.50; and (b) A heatmap of FFAs and EFAs of GC-MS contributing to the classification of PLS-DA [Variable Importance in the Projection (VIP) value $\geq 1$ ]. 
Table 2. Identification of FFAs and EFAs from the rat serum analyzed by GC-MS.

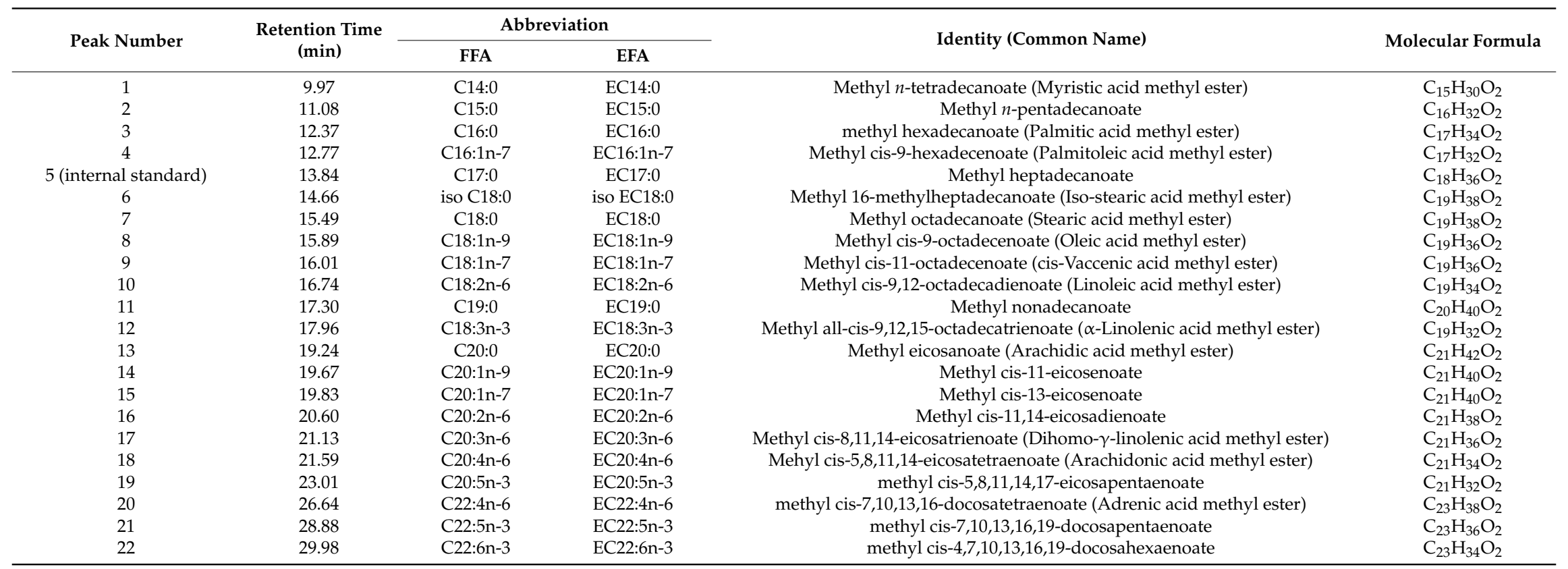


Figure 7 shows the normalized serum levels of EC22:4n-6 and EC22:5n-3, the ratio of esterified arachidonic acid to esterified dihomo- $\gamma$-linolenic acid (EC20:4n-6/EC20:3n-6), the ratio of esterified adrenic acid to esterified arachidonic acid (EC22:4n-6/EC20:4n-6), and the ratio of esterified DPA to esterified eicosapentaenoic acid (EPA) (EC22:5n-3/EC20:5n-3) among normal control, HCD model, HCD treatment with simvastatin and ACS groups. There were significantly decreased level of DPA, adrenic acid, ratio of EC20:4n-6/EC20:3n-6, EC22:4n-6/EC20:4n-6 and EC22:5n-3/EC20:5n-3 in HCD model group. However, treatment with ACS could upregulate all $(p<0.05)$ compared with HCD group.

EC22:4n-6

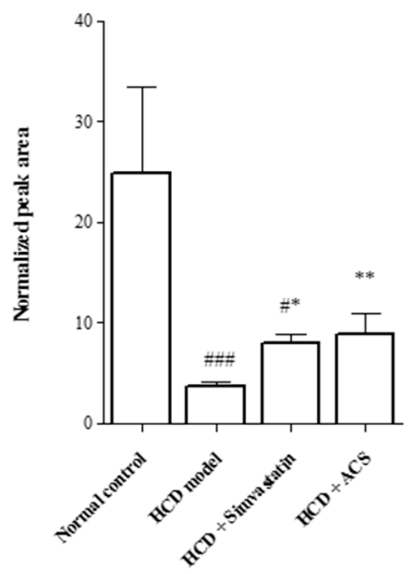

EC22:5n-3

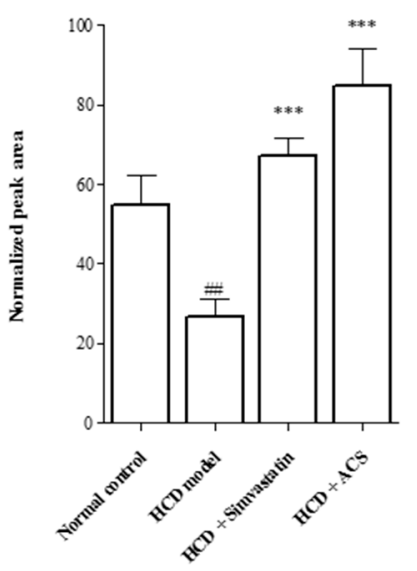

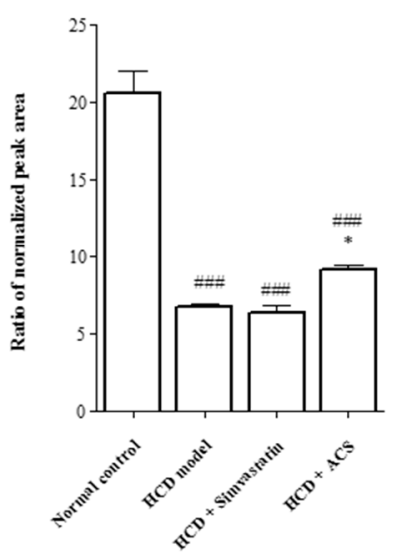
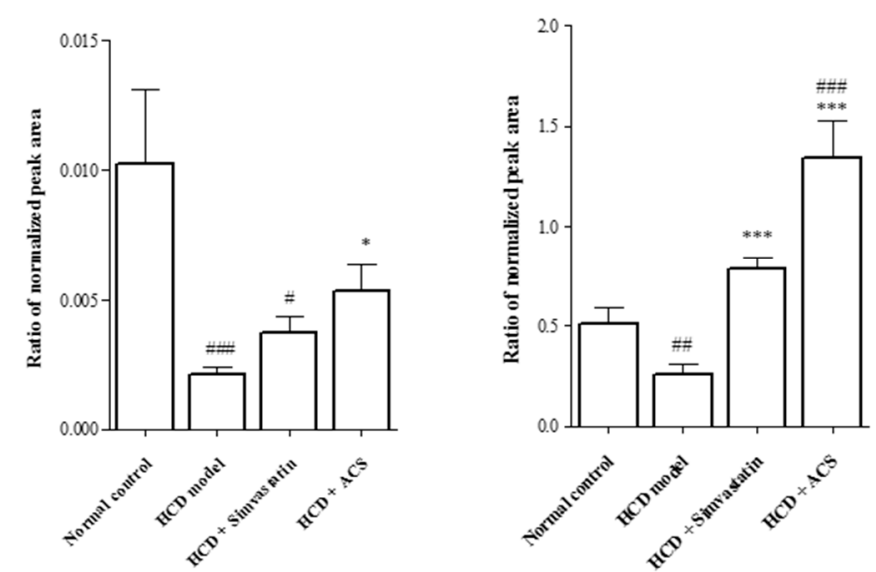

Figure 7. The normalized serum levels of EC22:4n-6, EC22:5n-3, and ratio of EC20:4n-6/EC20:3n-6, EC22:4n-6/EC20:4n-6 and EC22:5n-3/EC20:5n-3. Data are expressed as means \pm SEM, $(n=6-8)$. One-way ANOVA test after $\log 2$ transformation to minimize variance, Tukey HSD post hoc test. $\# p<0.05$, \#\# $p<0.01$ and \#\#\# $p<0.001$ represent significant differences when compared with the normal control group. ${ }^{*} p<0.05,{ }^{* *} p<0.01$ and ${ }^{* *} p<0.001$ represent significant differences when compared with the HCD group.

\subsection{Effects on the Protein Expression of PPAR in the Liver}

From the results shown in Figure 8, HCD significantly decreased the PPAR $\alpha$ protein level $(p<0.001)$. Interestingly, treating the rats with ACS $(p<0.01)$ and simvastatin $(p<0.05)$ could restore the protein expression of PPAR $\alpha$ close to the control under the same experimental conditions. 

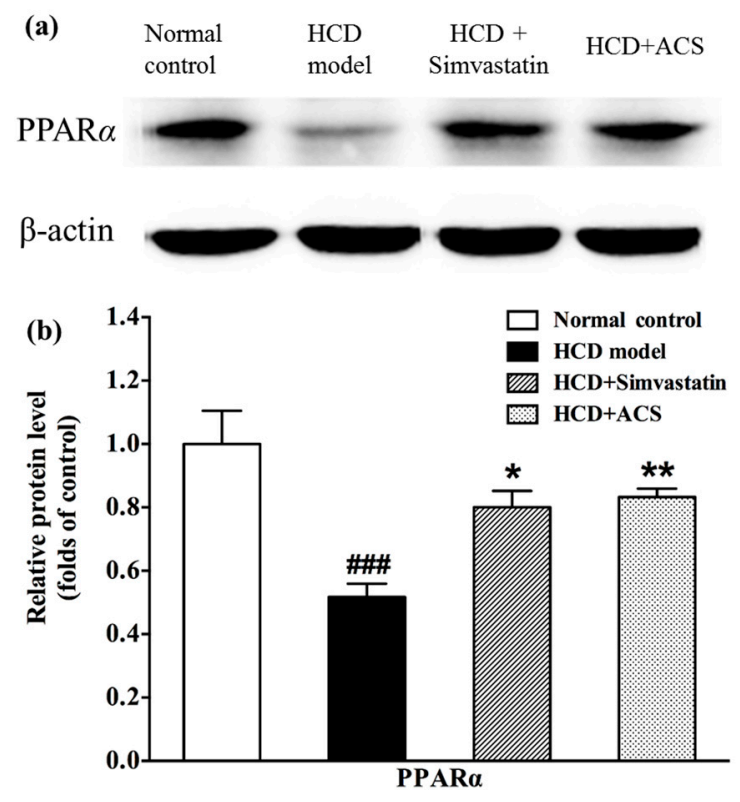

Figure 8. Effects of ACS extract on protein expression of hepatic PPAR $\alpha$ of rats: (a) protein expression of PPAR $\alpha$ in the liver of rats was changed by simvastatin and ACS; and (b) the protein levels were expressed relative to $\beta$-actin. Data are expressed as means $\pm \operatorname{SEM}(n=7)$. One-way ANOVA, Tukey HSD post hoc test. \#\#\# $p<0.001$ represent significant differences when compared with the Control group. ${ }^{*} p<0.05$ and ${ }^{* *} p<0.01$ represent significant differences when compared with the HCD group.

\section{Discussion}

Diet plays an important role in the control of cholesterol homeostasis and the main reason leading to the development of hyperlipidemia, atherosclerosis and other CVDs because of the consumption of cholesterol-enriched diet over long period of time [26]. TCMs possessing hypocholesterolemic and/or hypolipidemic properties are commonly used as functional foods to prevent the development of CVDs in the Chinese community [27-29]. The present study showed that ACS extract supplementation at $600 \mathrm{mg} / \mathrm{kg} /$ day for four weeks resulted in suppression of diet-induced hypercholesterolaemia, evidenced by the reduction of serum total cholesterols, LDL-C and atherogenic index, similar to the group given by the positive control, simvastatin.

The pharmacological activities of ACS have been focused and its flavonoid fraction was proved as active constituents. In the present study, the total phenolic content of dried ACS extract was determined by Folin-Ciocalteu method and its chemical constituents of dried ACS were further examined by mass spectrometry. ACS exhibited antioxidant DPPH radical scavenging activity. Multiclass compounds (a total of 36 compounds) including amino acid, flavonoids and their glycosides were identified (eight compounds were identified with standards) or tentatively identified. Some of these compounds have been reported to possess different biological activities. For example, isoquercitrin had a protective effect against acetaminophen induced liver injury [30]; complanatuside exhibited strong inhibition on lipopolysaccharide-induced nitric oxide release by macrophages [31]; and quercetin demonstrated a protective effect on high-fat diet-induced non-alcoholic fatty liver disease in mice mediated by modulating intestinal microbiota imbalance and related gut-liver axis activation [32].

Metabolomics, i.e., systematic analysis of all metabolites and metabolic pathways in a given biological system, has been increasingly recognized in biomarker discovery and understanding disease mechanisms. Good recovery and high analytical reproducibility of the metabolite detection in this study demonstrated that the presented methodologies have the reliability and robustness as required by a metabolomics profiling study. As a result, it could ensure the changes among the different groups observed from the statistical analysis were biologically related. 
In the result of GC-MS of EFA and FFA of serum of rat with HCD, it was obvious that the level of DPA and adrenic acid decreased significantly. Dihomo- $\gamma$-linolenic acid and arachidonic acid are key players in the synthetic pathway for pro-inflammatory series 2 prostaglandins and leukotrienes and elevated levels of those polyunsaturated fatty acid (PUFA) may contribute to the inflammatory phenotype in obesity or metabolic syndrome [33,34]. The obtained results indicated that suppression on transformation from dihomo- $\gamma$-linolenic acid and arachidonic acid to adrenic acid was presented in rat fed with HCD. Based on the route of biosynthesis of the $\omega-6$ family of PUFA [35], the following increased product possibly resulted in up-regulation of pro-inflammatory eicosanoids synthesis. In the opposite, the result of treatment of ACS showed that adrenic acid, ratio of arachidonic acid to dihomo- $\gamma$-linolenic acid and ratio of adrenic acid to arachidonic acid were up-regulated significantly $(p<0.05)$. In addition, DPA and its ratio to EPA were elevated significantly $(p<0.001)$, which was probably transformed to more anti-inflammatory eicosanoids in the pathway of biosynthesis of $\omega-3$ PUFA [35].

PPARs are members of the nuclear receptor superfamily of ligand-binding transcription factors that control the genes regulation involved in lipid and glucose metabolism linked to energy homeostasis, adipogenesis, inflammatory responses [36]. Based on the results obtained in GC-MS metabolomics platform, the protein expression of $\operatorname{PPAR} \alpha$, which is expressed primarily in the liver, was further investigated on the effect of $\beta$-oxidation of fatty acid after ACS treatment. The present study found that the protein expression of PPAR $\alpha$ of the treatment group with ACS was upregulated significantly. This implied that the $\beta$-oxidation of fatty acids were enhanced. Archana Mishra's study demonstrated that oxidized $\omega-3$ PUFA inhibited pro-inflammatory responses such as leukocyte adhesion receptor and chemokine expression through inhibition of NF- $\kappa B$ via a PPAR-dependent pathway [37]. In ACS treated group, the increased $\omega-3$ PUFA, and free and esterified DPA that was finally converted to DHA (free or esterified DHA in this study did not have significant difference between groups) was probably inhibited pro-inflammatory responses by oxidation via the same PPAR $\alpha$-dependent mechanism. Thus, a detail study on the gene and protein expression involved in fatty acid oxidation at liver such as carnitine palmitoyltransferase I (CPT1) or acyl-CoA oxidase 1 (ACOX1) is needed for further investigation to consolidate the mechanism behind on the treatment of ACS.

\section{Conclusions}

The dried 70\% ethanol extract isolated from ACS contains rich antioxidant phenolic compounds, which was further identified mainly as flavonoids and flavonoid glycosides by UPLC-ESI-Orbitrap-MS. The present results demonstrated that the ACS significantly reduced the serum total cholesterols and LDL-C in the rats fed with HCD after four-week treatment. Fatty acid profiling analysis also pointed out that DPA in serum of treatment group with ACS has been restored back to normal. One of the hypocholesterolemic activities is associated with its promotion of the $\beta$-oxidation of fatty acids in the liver, as demonstrated by the increased protein expressions of PPAR $\alpha$.

Acknowledgments: This study was supported by the Hong Kong Chinese Material Medica Standards Project, the Shenzhen Basic Research Program (JCYJ20160229173844278, JCYJ20151030164008764, JCYJ20160330171116798, and JCYJ20140819153305694), the National Natural Science Foundation of China (81303203), and the Research Grant Council (RGC) of the Hong Kong Special Administrative Region (Grant No.: UGC/FDS25/M06/16). We are also very grateful for the Large Equipment Funds, the University Research Facility in Chemical and Environmental Analysis and Life Sciences of the Hong Kong Polytechnic University to support the instruments used in this study.

Author Contributions: All authors conceived and designed the experiments; Tung-Ting Sham, Song-Yun Tang, Jian-Hong $\mathrm{Wu}$ and Huan Zhang performed the experiments and analyzed the data; and Tung-Ting Sham and On-Chi Chan wrote the paper.

Conflicts of Interest: The authors declare no conflict of interest. 


\section{References}

1. Ng, Y.F.; Tang, P.C.T.; Sham, T.T.; Lam, W.S.; Mok, D.K.W.; Chan, S.W. Semen Astragali Complanati: An ethnopharmacological, phytochemical and pharmacological review. J. Ethnopharmacol. 2014, 155, 39-53. [CrossRef] [PubMed]

2. Chinese Pharmacopoeia Commission. Pharmacopoeia of the People's Republic of China; Chinese Medical Science Press: Beijing, China, 2015; Volume 1.

3. Hong Kong Chinese Materia Medica Standards Office. Hong Kong Chinese Materia Medica Standards—Astragali Complanati Semen; Chinese Medicine Division, Department of Health, HKSAR Goverment: Hong Kong, China, 2013; Volume 6.

4. Xue, B.; Li, J.; Chai, Q.; Liu, Z.; Chen, L. Effect of total flavonoid fraction of Astragalus complanatus R. Brown on angiotensin II-induced portal-vein contraction in hypertensive rats. Phytomedicine 2008, 15, 759-762. [CrossRef] [PubMed]

5. Liu, C.Y.; Gu, Z.L.; Zhou, W.X.; Guo, C.Y. Effect of Astragalus complanatus flavonoid on anti-liver fibrosis in rats. World J. Gastroenterol. 2005, 11, 5782-5786. [CrossRef] [PubMed]

6. Zhang, Q.A.; Fan, X.H.; Zhang, Z.Q.; Li, T.; Zhu, C.P.; Zhang, X.R.; Song, W. Extraction, antioxidant capacity and identification of Semen Astragali Complanati (Astragalus complanatus R. Br.) phenolics. Food Chem. 2013, 141, 1295-1300. [CrossRef] [PubMed]

7. Gorrochategui, E.; Jaumot, J.; Lacorte, S.; Tauler, R. Data analysis strategies for targeted and untargeted LC-MS metabolomic studies: Overview and workflow. TrAC Trends Anal. Chem. 2016, 82, 425-442. [CrossRef]

8. Nagana Gowda, G.A.; Raftery, D. Recent Advances in NMR-Based Metabolomics. Anal. Chem. 2017, 89, 490-510. [CrossRef] [PubMed]

9. Ussher, J.R.; Elmariah, S.; Gerszten, R.E.; Dyck, J.R.B. The Emerging Role of Metabolomics in the Diagnosis and Prognosis of Cardiovascular Disease. J. Am. Coll. Cardiol. 2016, 68, 2850-2870. [CrossRef] [PubMed]

10. Guo, L.; Milburn, M.V.; Ryals, J.A.; Lonergan, S.C.; Mitchell, M.W.; Wulff, J.E.; Alexander, D.C.; Evans, A.M.; Bridgewater, B.; Miller, L.; et al. Plasma metabolomic profiles enhance precision medicine for volunteers of normal health. Proc. Natl. Acad. Sci. USA 2015, 112, E4901-E4910. [CrossRef] [PubMed]

11. Hu, C.; Xu, G. Metabolomics and traditional Chinese medicine. Trends Anal. Chem. 2014, 61, $207-214$. [CrossRef]

12. Hocher, B.; Adamski, J. Metabolomics for clinical use and research in chronic kidney disease. Nat. Rev. Nephrol. 2017, 13, 269-284. [CrossRef] [PubMed]

13. Pallares-Méndez, R.; Aguilar-Salinas, C.A.; Cruz-Bautista, I.; del Bosque-Plata, L. Metabolomics in diabetes, a review. Ann. Med. 2016, 48, 89-102. [CrossRef] [PubMed]

14. Navar-Boggan, A.M.; Peterson, E.D.; D’Agostino, R.B.; Neely, B.; Sniderman, A.D.; Pencina, M.J. Hyperlipidemia in Early Adulthood Increases Long-Term Risk of Coronary Heart Disease. Circulation 2015, 131, 451-458. [CrossRef] [PubMed]

15. Kazdova, L. Relationship of Circulating Fatty Acid Profile to Metabolic Disorders Associated with Insulin Resistance. EBioMedicine 2015, 2, 1308-1309. [CrossRef] [PubMed]

16. Kusunoki, J.; Kanatani, A.; Moller, D.E. Modulation of fatty acid metabolism as a potential approach to the treatment of obesity and the metabolic syndrome. Endocrine 2006, 29, 91-100. [CrossRef]

17. Boden, G.; Shulman, G.I. Free fatty acids in obesity and type 2 diabetes: defining their role in the development of insulin resistance and $\beta$-cell dysfunction. Eur. J. Clin. Investig. 2002, 32, 14. [CrossRef]

18. Boden, G. Obesity, insulin resistance and free fatty acids. Curr. Opin. Endocrinol. Diabetes Obes. 2011, 18, 139-143. [CrossRef] [PubMed]

19. Singleton, V.L.; Orthofer, R.; Lamuela-Raventós, R.M. Analysis of total phenols and other oxidation substrates and antioxidants by means of folin-ciocalteu reagent. In Methods in Enzymology; Lester, P., Ed.; Academic Press: San Diego, CA, USA, 1999; Volume 299, pp. 152-178.

20. Guo, D.J.; Cheng, H.L.; Chan, S.W.; Yu, P.H.F. Antioxidative activities and the total phenolic contents of tonic Chinese Medicinal Herbs. Inflammopharmacology 2008, 16, 201-207. [CrossRef] [PubMed]

21. Kwok, C.-Y.; Wong, C.N.-Y.; Yau, M.Y.-C.; Yu, P.H.-F.; Au, A.L.S.; Poon, C.C.-W.; Seto, S.-W.; Lam, T.-Y.; Kwan, Y.-W.; Chan, S.-W. Consumption of dried fruit of Crataegus pinnatifida (hawthorn) suppresses high-cholesterol diet-induced hypercholesterolemia in rats. J. Funct. Foods 2010, 2, 179-186. [CrossRef] 
22. Li, M.; Zhou, L.; Yang, D.; Li, T.; Li, W. Biochemical composition and antioxidant capacity of extracts from Podophyllum hexandrum rhizome. BMC Complement. Altern. Med. 2012, 12, 1472-6882. [CrossRef] [PubMed]

23. Yi, L.Z.; He, J.; Liang, Y.Z.; Yuan, D.L.; Chau, F.T. Plasma fatty acid metabolic profiling and biomarkers of type 2 diabetes mellitus based on GC/MS and PLS-LDA. FEBS Lett. 2006, 580, 6837-6845. [CrossRef] [PubMed]

24. Li, Y.; Wang, C.; Li, H.; Yu, T.; Tan, L. Simultaneous Determination of Formononetin, Calycosin and Rhamnocitrin from Astragalus Complanatus by UHPLC-MS-MS in Rat Plasma: Application to a Pharmacokinetic Study. J. Chromatogr. Sci. 2016, 54, 1605-1612. [CrossRef] [PubMed]

25. Zhang, Q.A.; Fan, X.H.; Li, T.; Zhang, Z.Q.; Liu, Y.K.; Li, X.P. Optimisation of ultrasound extraction for flavonoids from Semen Astragali Complanati and its identification by HPLC-DAD-MS/MS. Int. J. Food Sci. Technol. 2013, 48, 1970-1976. [CrossRef]

26. Ónody, A.; Csonka, C.; Giricz, Z.; Ferdinandy, P. Hyperlipidemia induced by a cholesterol-rich diet leads to enhanced peroxynitrite formation in rat hearts. Cardiovasc. Res. 2003, 58, 663-670. [CrossRef]

27. Chu, S.-M.; Shih, W.-T.; Yang, Y.-H.; Chen, P.-C.; Chu, Y.-H. Use of traditional Chinese medicine in patients with hyperlipidemia: A population-based study in Taiwan. J. Ethnopharmacol. 2015, 168, 129-135. [CrossRef] [PubMed]

28. Xie, W.; Zhao, Y.; Du, L. Emerging approaches of traditional Chinese medicine formulas for the treatment of hyperlipidemia. J. Ethnopharmacol. 2012, 140, 345-367. [CrossRef] [PubMed]

29. Sham, T.T.; Chan, C.O.; Wang, Y.H.; Yang, J.M.; Mok, D.K.W.; Chan, S.-W. A Review on the Traditional Chinese Medicinal Herbs and Formulae with Hypolipidemic Effect. BioMed Res. Int. 2014, 2014, 925302. [CrossRef] [PubMed]

30. Xie, W.; Wang, M.; Chen, C.; Zhang, X.; Melzig, M.F. Hepatoprotective effect of isoquercitrin against acetaminophen-induced liver injury. Life Sci. 2016, 152, 180-189. [CrossRef] [PubMed]

31. Wang, Z.-B.; Zhai, Y.-D.; Ma, Z.-P.; Yang, C.-J.; Pan, R.; Yu, J.-L.; Wang, Q.-H.; Yang, B.-Y.; Kuang, H.-X. Triterpenoids and Flavonoids from the Leaves of Astragalus membranaceus and Their Inhibitory Effects on Nitric Oxide Production. Chem. Biodivers. 2015, 12, 1575-1584. [CrossRef] [PubMed]

32. Porras, D.; Nistal, E.; Martínez-Flórez, S.; Pisonero-Vaquero, S.; Olcoz, J.L.; Jover, R.; González-Gallego, J.; García-Mediavilla, M.V.; Sánchez-Campos, S. Protective effect of quercetin on high-fat diet-induced non-alcoholic fatty liver disease in mice is mediated by modulating intestinal microbiota imbalance and related gut-liver axis activation. Free Radic. Biol. Med. 2017, 102, 188-202. [CrossRef] [PubMed]

33. Levin, G.; Duffin, K.L.; Obukowicz, M.G.; Hummert, S.L.; Fujiwara, H.; Needleman, P.; Raz, A. Differential metabolism of dihomo- $\gamma$-linolenic acid and arachidonic acid by cyclo-oxygenase-1 and cyclo-oxygenase-2: Implications for cellular synthesis of prostaglandin E1 and prostaglandin E2. Biochem. J. 2002, 365, 489-496. [CrossRef] [PubMed]

34. Iversen, L.; Fogh, K.; Kragballe, K. Effect of dihomogammalinolenic acid and its 15-lipoxygenase metabolite on eicosanoid metabolism by human mononuclear leukocytes in vitro: selective inhibition of the 5-lipoxygenase pathway. Arch. Dermatol. Res. 1992, 284, 222-226. [CrossRef] [PubMed]

35. Calder, P.C. Mechanisms of Action of (n-3) Fatty Acids. J. Nutr. 2012, 142, 592S-599S. [CrossRef] [PubMed]

36. Echeverría, F.; Ortiz, M.; Valenzuela, R.; Videla, L.A. Long-chain polyunsaturated fatty acids regulation of PPARs, signaling: Relationship to tissue development and aging. Prostaglandins Leukot. Essent. Fat. Acids 2016, 114, 28-34. [CrossRef] [PubMed]

37. Mishra, A.; Chaudhary, A.; Sethi, S. Oxidized Omega-3 Fatty Acids Inhibit NF-kB Activation via a PPAR $\alpha$-Dependent Pathway. Arterioscler. Thromb. Vasc. Biol. 2004, 24, 1621-1627. [CrossRef] [PubMed]

(C) 2017 by the authors. Licensee MDPI, Basel, Switzerland. This article is an open access article distributed under the terms and conditions of the Creative Commons Attribution (CC BY) license (http://creativecommons.org/licenses/by/4.0/). 